\title{
Enhanced catalytic activity for butane isomerization with alumina-promoted tungstated mesoporous zirconia
}

\author{
Chi-Chau Hwang ${ }^{\text {a }}$, Xiao-Rong Chen ${ }^{\text {a,c }}$, She-Tin Wong ${ }^{\text {a }}$, \\ Chang-Lin Chen ${ }^{\mathrm{c}}$, Chung-Yuan Mou ${ }^{\mathrm{a}, \mathrm{b}, *}$ \\ ${ }^{a}$ Department of Chemistry, National Taiwan University, Taipei 106, Taiwan \\ ${ }^{\mathrm{b}}$ Center of Condensed Matter Science, National Taiwan University, Taipei 106, Taiwan \\ ${ }^{\mathrm{c}}$ College of Chemistry and Chemical Engineering, Nanjing University of Technology, Nanjing 210009, China \\ Received 29 September 2006; received in revised form 19 December 2006; accepted 9 January 2007 \\ Available online 9 February 2007
}

\begin{abstract}
Mesoporous zirconia, synthesized from surfactant templating, was used to disperse alumina and tungstate as a catalyst $\left(\mathrm{denoted}\right.$ as $\left.\mathrm{AW} / \mathrm{m}-\mathrm{ZrO}{ }_{2}\right)$ for the isomerization of $n$-butane. At a relatively low temperature of calcination $\left(700{ }^{\circ} \mathrm{C}\right.$ ), the catalyst (AW/m-700) performed exceptionally well, both in maximum rate and stability, at a temperature of $250{ }^{\circ} \mathrm{C}$. This was lower than the temperature needed by other tungstated zirconia-based catalysts reported so far. This lower temperature of calcination leads to the presence of more Brönsted acid sites with higher acid strength. In comparison with the normal dense phase zirconia catalyst, $\mathrm{AW} / \mathrm{m}-\mathrm{ZrO}_{2}$ catalyst showed higher $n$-butane isomerization activity than the corresponding $\mathrm{AW} / \mathrm{d}-\mathrm{ZrO}_{2}$ catalyst, which has about the same surface area. The difference in catalytic activity was attributed to the higher degree of dispersion of tungstate on the surface of $\mathrm{m}-\mathrm{ZrO}_{2}$.
\end{abstract}

(C) 2007 Elsevier B.V. All rights reserved.

Keywords: Tungstated zirconia; Alkane isomerization; Mesoporous zirconia; EXAFS; XPS; Surface acidity

\section{Introduction}

Acid catalyzed skeletal isomerization reactions of $n$-alkanes are important in the chemical industry. However, under the worldwide trend for safer and cleaner processes, the conventional catalysts such as corrosive liquid acids and metal halides have to be replaced by the more environmental friendly halidefree solid acid catalysts. Zirconia-based solid acids, sulfated zirconia and tungstated zirconia, have thus received increasing attention recently.

Tungstated zirconia is in a class of solid acid catalyst that show promising prospects in the isomerization of normal alkanes [1-4]. Although tungstated zirconia is structurally more stable than sulfated zirconia, thus giving more steady performance in catalysis, it is also less active. This leads to higher reaction temperatures, usually above $300{ }^{\circ} \mathrm{C}$ for the

\footnotetext{
* Corresponding author at: Department of Chemistry, National Taiwan University, Taipei 106, Taiwan.

E-mail address: cymou@ntu.edu.tw (C.-Y. Mou).
}

isomerization of butane for example. High reaction temperatures are thermodynamically less favorable for the branched isomers. Thus, improving the catalytic activity of tungstated zirconia catalyst so that the reaction can be operated at lower temperatures is the goal of this work. In this research, two methods for increasing the catalytic activity of tungstated zirconia are employed: (a) using mesoporous zirconia [5] to increase the surface area and textural properties of the catalyst and (b) using alumina as the promoter of the catalyst, so that catalytic activities are not only promoted but also stabilized. Previously, we reported on the promotional effect of $\mathrm{Al}$ and $\mathrm{Ga}$ on butane isomerization over tungstated zirconia catalyst [6-8]. The improved activity of alumina promoted tungstated zirconia (AWZ) for $n$-butane isomerization was related to the prevention of crystalline $\mathrm{WO}_{3}$ phase [7] and to the increased acid sites [6] created by the $\mathrm{Al}$ promoter. However, the origin of the promoted activity is still not completely understood.

First, we briefly describe the preparation and characterization of alumina-promoted tungstated mesoporous zirconia $\left(\mathrm{AW} / \mathrm{m}-\mathrm{ZrO}_{2}\right)$ catalyst. Then, $n$-butane isomerization was used as the test reaction for the catalysis system. The mesoporous 
zirconia was made from cationic surfactant $\left(\mathrm{C}_{16} \mathrm{TAB}\right)$ templated sol-gel process [5,9]. The acidity of these catalysts was characterized by $\mathrm{NH}_{3}-\mathrm{TPD}$, in situ DRIFT spectroscopic analysis of chemisorbed $\mathrm{NH}_{3}$ and XPS analysis tungstate species. We are able to resolve the acid sites into Lewis and Brönsted components. The composition of the acid sites on $\mathrm{AW} / \mathrm{m}-\mathrm{ZrO}_{2}$ catalysts calcined at different temperatures was correlated to their catalytic performances. Besides the AW/m$\mathrm{ZrO}_{2}$ catalyst, we also synthesized the normal kind of dense phase zirconia $\left(\mathrm{d}-\mathrm{ZrO}_{2}\right)$ without $\mathrm{C}_{16} \mathrm{TAB}$, to make the dense phase alumina-tungstated zirconia $\left(\mathrm{AW} / \mathrm{d}-\mathrm{ZrO}_{2}\right)$. We compared the two different catalysts of their activities. We found that the catalytic activity for mesoporous $\mathrm{AW} / \mathrm{m}-\mathrm{ZrO}_{2}$ catalyst is a lot higher than that of dense phase $\mathrm{AW} / \mathrm{d}-\mathrm{ZrO}_{2}$. We then discuss the origin of the difference by comparison of the textural and acidity characterizations.

\section{Experimental}

\subsection{Preparation of the catalysts}

Mesoporous zirconia was made using the cationic surfactant hexadecyl trimethyl ammonium bromide $\left(\mathrm{C}_{16} \mathrm{TAB}\right)$-templated sol-gel process according to the method outlined by Ciesla et al. [5] (designated as $\mathrm{m}-\mathrm{ZrO}_{2}$ ). The details are in our previous report on sulfated mesoporous zirconia [9]. Alumina-promoted catalyst, $\mathrm{AW} / \mathrm{m}-\mathrm{ZrO}_{2}$, was prepared by simultaneous impregnation of the uncalcined $\mathrm{m}-\mathrm{ZrO}_{2}$ precursor with the required amount of ammonium tungstate and aluminum nitrate in $\mathrm{H}_{2} \mathrm{O}$ / $\mathrm{C}_{2} \mathrm{H}_{5} \mathrm{OH}$ solvent. Samples were dried at $100{ }^{\circ} \mathrm{C}$, and then calcined at one of several temperatures (from $630{ }^{\circ} \mathrm{C}$ to $850{ }^{\circ} \mathrm{C}$ ) in static air for $3 \mathrm{~h}$. For the purpose of comparison, a conventional dense phase catalyst $\left(\mathrm{AW} / \mathrm{d}-\mathrm{ZrO}_{2}\right)$ [10] was also prepared with similar loadings of $\mathrm{Al}$ and $\mathrm{W}$ but without the template. In the case of $\mathrm{AW} / \mathrm{d}-\mathrm{ZrO}_{2}$, amorphous zirconium hydroxide was used instead of the uncalcined $\mathrm{m}-\mathrm{ZrO}_{2}$ precursor. Here, d- $\mathrm{ZrO}_{2}$ represents dense-phase zirconia (without the template).

\subsection{Characterization techniques}

Elemental analysis was determined by inductively coupled plasma atomic emission spectroscopy (ICP-AES) using a Jarrel-Ash ICAP 9000 instrument. Carbon analysis was done with a Heraeus VarioEL-III instrument. Powdered X-ray diffraction (XRD) patterns were recorded on a PANalytical X'Pert PRO diffractometer using $\mathrm{Cu} \mathrm{K} \alpha$ radiation operating at $45 \mathrm{kV}$ and $40 \mathrm{~mA}$. $\mathrm{N}_{2}$ adsorption-desorption isotherm, BET surface area, and porosity data were determined at $77 \mathrm{~K}$ on a Micromeritics ASAP 2010 instrument. Ultraviolet-visible (UV-vis) absorption spectra were taken on a Hitachi U-3310 spectrophotometer.

$\mathrm{NH}_{3}$ temperature-programmed desorption $\left(\mathrm{NH}_{3}-\mathrm{TPD}\right)$ of samples was carried out on Micrometrics AutoChem 2910 instrument. Before $\mathrm{NH}_{3}$ adsorption, $0.2 \mathrm{~g}$ calcined sample was pretreated at $400{ }^{\circ} \mathrm{C}$ in flowing $\mathrm{He}$ for $1 \mathrm{~h}$. The $\mathrm{NH}_{3}$ adsorption was carried out at $100{ }^{\circ} \mathrm{C}$ and the desorption of $\mathrm{NH}_{3}$ was started at $100{ }^{\circ} \mathrm{C}$ and continued until $800{ }^{\circ} \mathrm{C}$ at $10{ }^{\circ} \mathrm{C} / \mathrm{min}$. The desorption process was monitored by a Quadruple Mass Spectrometer (Thermo ONIX ProLab) using the mass number $16\left(\mathrm{NH}_{2}{ }^{+}\right)$to obtain $\mathrm{NH}_{3}$-TPD profiles. In situ diffusereflectance infrared Fourier-transformed (DRIFT) spectra of ammonia chemisorbed on catalyst were taken with a Thermo Nicolet 380 FT-IR spectrometer. The sample was first dried at $400{ }^{\circ} \mathrm{C}$ for at least $1 \mathrm{~h}$ prior to ammonia adsorption. The adsorption of ammonia was done by flowing $5 \% \mathrm{NH}_{3} / \mathrm{N}_{2}$ mixture through the catalyst at $120{ }^{\circ} \mathrm{C}$ for $5 \mathrm{~min}$; the system was then flushed with dry $\mathrm{N}_{2}$ for $15 \mathrm{~min}$. The catalyst with adsorbed ammonia was then subjected to a desorption process at increasing temperatures. Spectra were recorded after the catalyst's temperature was held for $15 \mathrm{~min}$ at each temperature. $\mathrm{X}$-ray photoelectron spectroscopic (XPS) analysis was performed using a Thermo VG Scientific ESCALAB 250 instrument with a monochromatic $\mathrm{Al} \mathrm{K} \alpha$ radiation $(1486.8 \mathrm{eV})$ and under a residual pressure of $\sim 5 \times 10^{-10}$ Torr. Torr. The pyridine-adsorbed sample was first degassed ex situ under vacuum at about $120{ }^{\circ} \mathrm{C}$ for $0.5 \mathrm{~h}$. The pretreated sample was then transferred into the XPS instrument and spectra were collected in the $\mathrm{N} 1 \mathrm{~s}$ region. Charge effects were compensated by electron flux from a flooding gun and the $\mathrm{Zr} 3 \mathrm{~d}_{5 / 2}$ binding energy was set at $182.2 \mathrm{eV}$. The spectral profiles were deconvoluted into peaks by using XPSPEAK software from RCSMS lab.

The W-L $\mathrm{L}_{\mathrm{III}}$-edge extended X-ray absorption fine structure (EXAFS) study was performed at the National Synchrotron Radiation Research Center in Hsinchu, Taiwan. The electron storage ring was operated at about $1.5 \mathrm{GeV}$ with a ring current of about $200 \mathrm{~mA}$.

\subsection{Catalytic study}

Each catalytic reaction was carried out in a fixed bed continuous flow quartz reactor at atmospheric pressure. The catalyst (usually $1.0 \mathrm{~g}$ ) was first pressed into 40-60 mesh (0.8$1.0 \mathrm{~mm}$ diameter) particles and mixed with quartz sand. It was then pretreated under air flow at $450{ }^{\circ} \mathrm{C}$ for $3 \mathrm{~h}$, and then reduced with $\mathrm{H}_{2}$ at $300{ }^{\circ} \mathrm{C}$ for $1 \mathrm{~h}$. After flushing the system with $\mathrm{N}_{2}$ at the reaction temperature for $0.5 \mathrm{~h}$, the reaction was started by introducing a mixture of $n$-butane and $\mathrm{H}_{2}(n$ $\mathrm{C}_{4}: \mathrm{H}_{2}=1: 10, \mathrm{v} / \mathrm{v}$ ) at a total inlet flow rate of $15.5 \mathrm{ml} \mathrm{min}^{-1}$. The reaction product was analyzed by an on-lined Agilent $6890 \mathrm{~N}$ gas chromatograph equipped with a flame ionization detector and a $60 \mathrm{~m} \mathrm{DB}-1$ column.

\section{Results}

\subsection{Structure study}

Before we advance onto the catalytic properties of AW/m$\mathrm{ZrO}_{2}$ catalysts, we should have a clear idea about their textural properties. More importantly, we would like to examine the effect of calcination temperature on the stability of these catalysts. The effect of doped species on the thermal phase transformation of zirconia, however, has been studied. Dopants 


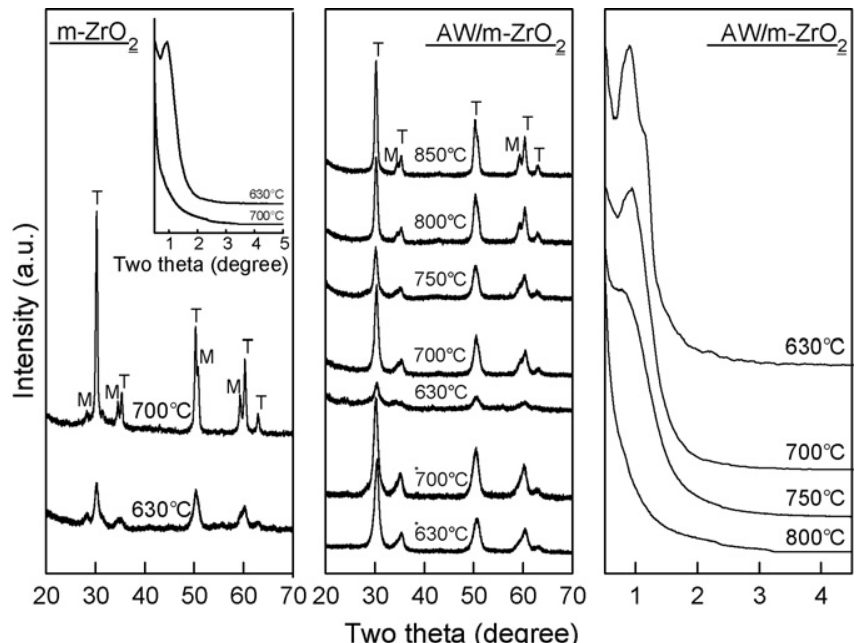

Fig. 1. XRD patterns of $\mathrm{m}-\mathrm{ZrO} \mathrm{r}_{2}$ and $\mathrm{AW} / \mathrm{m}-\mathrm{ZrO}_{2}$ catalysts calcined at different temperatures. *Sample of $\mathrm{AW} / \mathrm{d}-\mathrm{ZrO}_{2}$.

such as aluminum [9] and tungsten [11] can retard the transformation from tetragonal to monoclinic phase of zirconia. The tetragonal phase of zirconia is thought to play a vital role in $n$-butane isomerization reaction [12]. In this study, we found that AW not only retards the phase transformation of $\mathrm{m}-\mathrm{ZrO}_{2}$ but also leads to an increase of its average pore size.

Fig. 1 shows the XRD patterns of $\mathrm{m}-\mathrm{ZrO}_{2}$ and $\mathrm{AW} / \mathrm{m}-\mathrm{ZrO}_{2}$ calcined at different temperatures. In our study, $630{ }^{\circ} \mathrm{C}$ is the minimum calcination temperature required to generate the tetragonal phase of $\mathrm{m}-\mathrm{ZrO} \mathrm{r}_{2}$ in $\mathrm{AW} / \mathrm{m}-\mathrm{ZrO}_{2}$, which is crucial for the $n$-butane isomerization reaction. At $630{ }^{\circ} \mathrm{C}$, only the tetragonal phase of zirconia (peaks denoted as $\mathrm{T}$ ) is prominent in $\mathrm{AW} / \mathrm{m}-\mathrm{ZrO}_{2}$ while the monoclinic phase of zirconia (peaks denoted as $\mathrm{M}$ ) is also present in the case of pure $\mathrm{m}-\mathrm{ZrO}_{2}$.
Obviously, the presence of $\mathrm{AW}$ on $\mathrm{m}-\mathrm{ZrO}_{2}$ surface retards its transformation from tetragonal phase to monoclinic phase. This phenomenon was also observed in alumina-promoted sulfated $\mathrm{m}-\mathrm{ZrO}_{2}\left(\mathrm{AS} / \mathrm{m}-\mathrm{ZrO}_{2}\right)$ [9]. Its tetragonal phase of zirconia also becomes better developed. On the other hand, mixed tetragonal and monoclinic dense-phases were obtained in the case of pure $\mathrm{m}-\mathrm{ZrO}_{2}$.

The AW/m-630 and AW/m-700 catalysts exhibited a single peak at $0.9-1.0$ that is due to the mesostructure. Previously, we have examined the mesostructure of the support $\mathrm{m}-\mathrm{ZrO}_{2}$ and found that the mesopores are of worm-like structure [9]. When the calcination temperature was increased above $750{ }^{\circ} \mathrm{C}$, the XRD peak in the low angle region almost vanished, which implies collapse of the mesostructure. For alumina-doped AW/ $\mathrm{m}-\mathrm{ZrO}_{2}$, the monoclinic phase of zirconia only starts to develop after it was calcined at $800{ }^{\circ} \mathrm{C}$, which is near its structural collapse point.

Interestingly, we also found that the average pore sizes of $\mathrm{m}$ $\mathrm{ZrO}_{2}$ and $\mathrm{AW} / \mathrm{m}-\mathrm{ZrO}_{2}$ catalysts can be expanded by increasing the calcination temperature. Fig. 2 shows the $\mathrm{N}_{2}$ adsorptiondesorption isotherms and the corresponding pore size distribution for these calcined samples. At $630^{\circ} \mathrm{C}$, the hysteresis originally seen in $\mathrm{m}-\mathrm{ZrO}_{2}$ diminished after $\mathrm{AW}$ was loaded onto it. Besides, the total volume of $\mathrm{N}_{2}$ adsorbed also decreased in $\mathrm{AW} / \mathrm{m}-\mathrm{ZrO}_{2}$. Apparently, some of the loaded AW must have diffused into the channels of this catalyst. We have tried to use HR-TEM to directly locate $\mathrm{Al}$ and $\mathrm{W}$ in AW/ $\mathrm{m}-\mathrm{ZrO}_{2}$. Because of the high absorption of electron by W, however, the TEM images are too dark to identify the position of $\mathrm{W}$ on $\mathrm{m}-\mathrm{ZrO}_{2}$. Table 1 summarizes the results of the textural properties of these samples.

The two samples $\mathrm{m}-\mathrm{ZrO}_{2}$ and $\mathrm{AW} / \mathrm{m}-\mathrm{ZrO}_{2}$ behaved differently as the calcination temperature was increased to

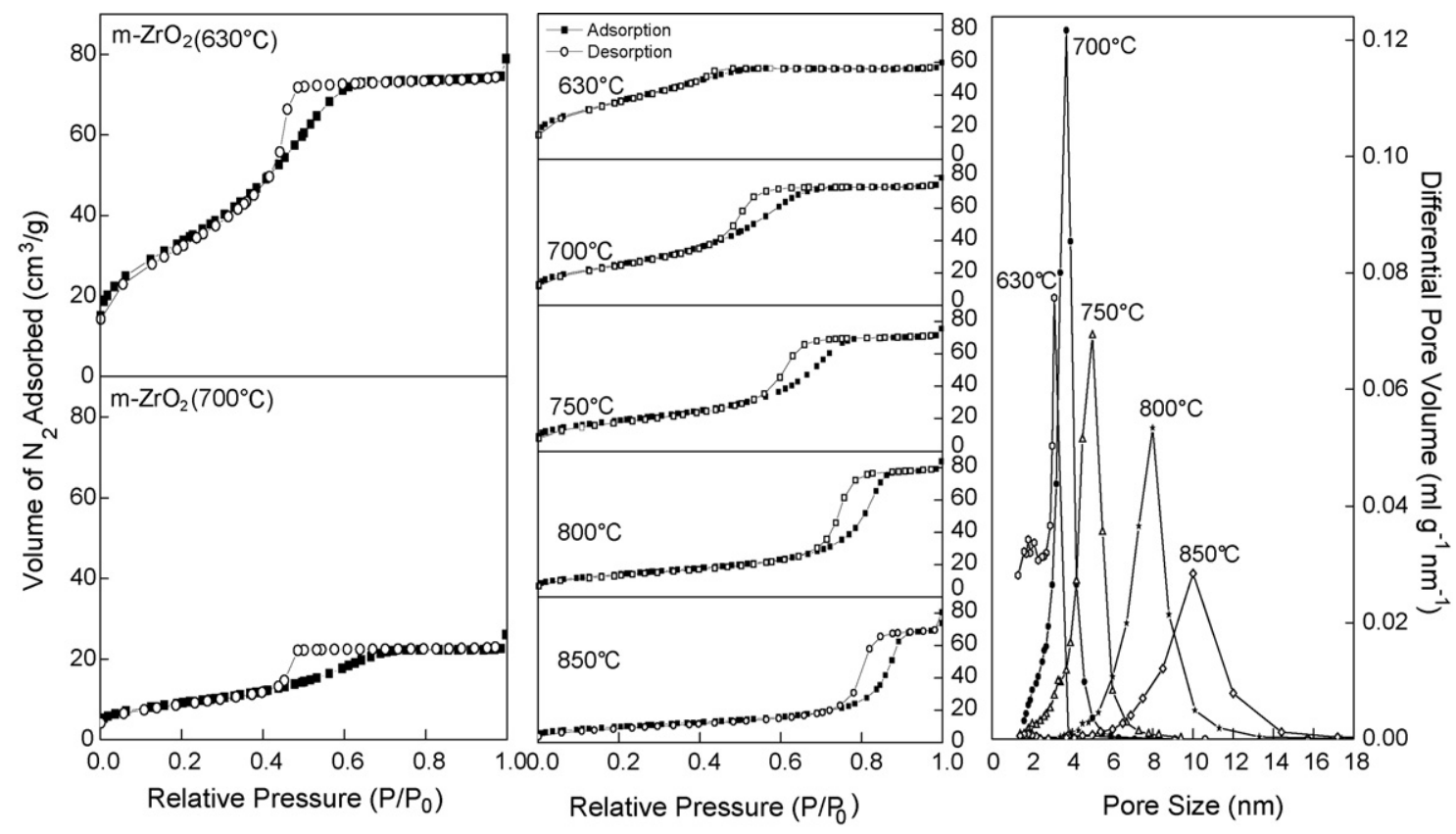

Fig. 2. $\mathrm{N}_{2}$ adsorption-desorption isotherms of $\mathrm{m}-\mathrm{ZrO}_{2}$ (left), $\mathrm{AW} / \mathrm{m}-\mathrm{ZrO}_{2}$ (middle), and pore size distribution of $\mathrm{AW} / \mathrm{m}-\mathrm{ZrO}{ }_{2}$ (right) catalysts calcined at different temperatures. 
Table 1

The textural and catalytic properties of catalysts

\begin{tabular}{|c|c|c|c|c|c|c|c|}
\hline Catalyst & $\begin{array}{l}\mathrm{W}^{\mathrm{a}} \\
(\mathrm{wt} \%)\end{array}$ & $\begin{array}{l}\mathrm{Al}^{\mathrm{a}} \\
(\mathrm{wt} . \%)\end{array}$ & $\begin{array}{l}\text { Surface } \\
\text { area }^{b}\left(\mathrm{~m}^{2} \mathrm{~g}^{-1}\right)\end{array}$ & $\begin{array}{l}\text { Pore size } \\
(\mathrm{nm})\end{array}$ & $\begin{array}{l}\text { Pore volume } \\
\left(\mathrm{ml} \mathrm{g}^{-1}\right)\end{array}$ & $\begin{array}{l}\text { W surface density } \\
\left(\text { atom nm }{ }^{-2} \text { ) }\right.\end{array}$ & $\begin{array}{l}\mathrm{TON}^{\mathrm{c}} \\
\left(\mu \mathrm{mol} \mathrm{g}{ }^{-1} \mathrm{~s}^{-1}\right)\end{array}$ \\
\hline AW/m-630 & 7.91 & 1.34 & 134 & 3.1 & 0.08 & 2.1 & 0.0973 \\
\hline AW/m-700 & 8.69 & 1.52 & 103 & 3.7 & 0.12 & 3.1 & 0.1860 \\
\hline $\mathrm{AW} / \mathrm{m}-750$ & 6.87 & 1.48 & 68 & 5.0 & 0.10 & 3.3 & 0.0315 \\
\hline AW/m-800 & 6.67 & 1.32 & 51 & 8.0 & 0.09 & 4.2 & 0.0019 \\
\hline AW/d-700 & 10.4 & 0.93 & 103 & 3.9 & 0.14 & 3.3 & 0.0007 \\
\hline $\mathrm{m}-700$ & - & - & 33 & 3.5 & 0.03 & - & 0.0002 \\
\hline AS/m-630 & - & 1.45 & 121 & 3.1 & 0.09 & - & 0.6220 \\
\hline
\end{tabular}

${ }^{\text {a }}$ Determined from ICP-AES.

b Determined from $\mathrm{N}_{2}$ adsorption-desorption isotherm at $77 \mathrm{~K}$.

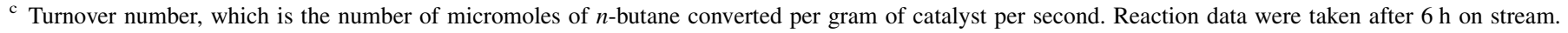

$700{ }^{\circ} \mathrm{C}$. In the case of pure $\mathrm{m}-\mathrm{ZrO}_{2}$, a great loss of the volume of $\mathrm{N}_{2}$ adsorbed occurred, indicating a collapse of its mesoporous structure. Conversely, the volume of $\mathrm{N}_{2}$ adsorbed increased slightly in $\mathrm{AW} / \mathrm{m}-\mathrm{ZrO}_{2}$ and a hysteresis loop appeared concurrently. This hysteresis loop later shifted to higher $P /$ $P_{0}$ values. The average pore sizes were enlarged as $\mathrm{AW} / \mathrm{m}-\mathrm{ZrO}_{2}$ was calcined at higher temperatures. As the pore size is enlarged, the surface area decreased due to increased wall thickness (Table 1). The pore volume increased for the same reason. At $750{ }^{\circ} \mathrm{C}$, the pore volume decreases again and this signifies the beginning of structural collapse. This observed temperature of structural instability is quite consistent with the XRD result for monoclinic zirconia formation at $800{ }^{\circ} \mathrm{C}$. On the other hand, similar temperature treatment for pure $\mathrm{m}-\mathrm{ZrO}_{2}$ caused its pore structure to collapse rapidly, so the dense-phase zirconia, with very low surface area, is formed at $700{ }^{\circ} \mathrm{C}$. For $\mathrm{AW} / \mathrm{m}-\mathrm{ZrO}_{2}$, the $\mathrm{W}$ surface density increased as the calcination temperature increased. The $\mathrm{W}$ atom surface density of AW/d700 is $3.3 \mathrm{~nm}^{-2}$, nearly equals to the densities of $\mathrm{AW} / \mathrm{m}-700$ and AW/m-750. This surface density is nearly equal to the monolayer coverage of tungsten oxide on zirconia, which is $3.5 \mathrm{~nm}^{-2}$. Recently, we have shown for dense phase zirconia that such loading of $\mathrm{W}$ is close to optimum catalytic activity for pentane isomerization [10].

In summary, $700{ }^{\circ} \mathrm{C}$ seems to be the optimum calcination temperature for obtaining maximum loadings of $\mathrm{W}$ and $\mathrm{Al}$ shown in Table 1 for the $\mathrm{AW} / \mathrm{m}-\mathrm{ZrO}_{2}$ catalyst; a fully developed tetragonal phase $\mathrm{m}-\mathrm{ZrO}_{2}$ of high porosity can be obtained. The porosity properties of the sample calcined at $630{ }^{\circ} \mathrm{C}$ are poor even though the same tetragonal phase of $\mathrm{m}-\mathrm{ZrO}_{2}$ can be obtained. Therefore, the choice of calcination temperature is very important for this system. The improved textural property of the catalyst at $700{ }^{\circ} \mathrm{C}$ should have a positive effect on $\mathrm{AW} / \mathrm{m}$ 700 catalytic performance in $n$-butane isomerization reactions (see Section 3.4).

\subsection{Acidity of the catalysts}

In $n$-butane isomerization, the Brönsted acid sites play a very important role. They are responsible for the protonation of butene formed from the dehydrogenation of $n$-butane, and this reaction leads further to the formation of carbene intermediates for the isomerization reaction [13]. The Brönsted acidity thus has a direct influence on the isomerization rate and coke formation of $\mathrm{AW} / \mathrm{m}-\mathrm{ZrO}_{2}$ catalyst in this reaction.

To research the acidity of our catalysts, we employed TPD and in situ DRIFT techniques to study their surface acidity. For both $\mathrm{AW} / \mathrm{m}-\mathrm{ZrO}_{2}$ and $\mathrm{AW} / \mathrm{d}-\mathrm{ZrO}_{2}$ catalysts, we employed temperature programmed ammonia desorption ( $\left.\mathrm{NH}_{3}-\mathrm{TPD}\right)$ to study the amount and strength of acid sites on solid acid catalysts. We first investigated the total acid sites and acid strength of AW/m-630, AW/m-700, and AW/d-700, as shown in Fig. 3. The desorption temperature (appearing at $\sim 260{ }^{\circ} \mathrm{C}$ ) for the dense phase catalyst AW/d-700 is lower than those of AW/ $\mathrm{m}-630$ and $\mathrm{AW} / \mathrm{m}-700 \quad\left(\sim 295^{\circ} \mathrm{C}\right)$. The integrated $\mathrm{NH}_{3}$ desorption profiles are calculated as the relative total acid sites. The total acid sites of AW/d-700 are the lowest among the

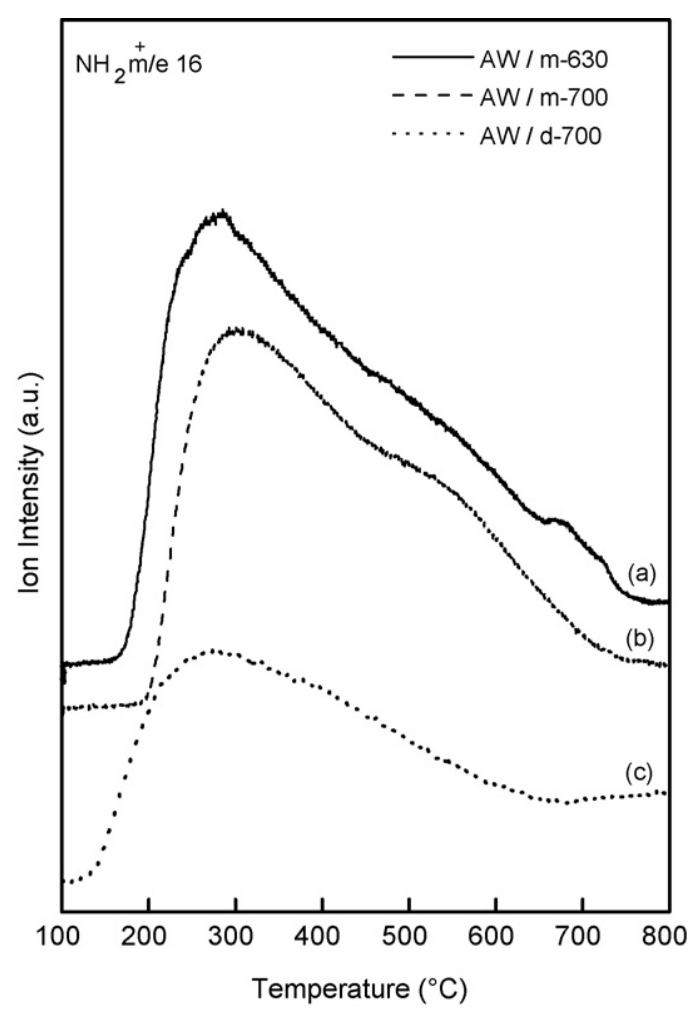

Fig. 3. $\mathrm{NH}_{3}$-TPD profiles of (a) AW/m-630, (b) AW/m-700, and (c) AW/d-700. 
samples. The mesoporous structured zirconia seems to favor the formation of stronger acid sites and enhanced the total acid sites at the same time.

The DRIFT results of chemisorbed ammonia are compared on AW/m-630, AW/m-700, and AW/m-750 (Fig. 4). The band at $1417 \mathrm{~cm}^{-1}$ (denoted as B) and a small shoulder at about $1670 \mathrm{~cm}^{-1}$ (denoted as B) correspond to $\mathrm{NH}_{4}^{+}$on Brönsted acid sites [6]. The band due to $\mathrm{NH}_{3}$ coordinated to Lewis acid sites, appears at $1606 \mathrm{~cm}^{-1}$ (L). All the bands decrease in intensity with increasing desorption temperatures, indicating the loss of $\mathrm{NH}_{3}$ adsorbed on Brönsted and Lewis acid sites. However, it seems that a Brönsted acid site corresponding to the $1417 \mathrm{~cm}^{-1}$ peak is stronger than Lewis acid sites since it still retains a significant amount of $\mathrm{NH}_{3}$ at $400{ }^{\circ} \mathrm{C}$, whereas the $\mathrm{NH}_{3}$ adsorbed on Lewis acid sites is almost completely desorbed. With respect to the calcination temperature, the lower the calcination temperature, the more Brönsted acid sites there are, in the order of $\mathrm{AW} / \mathrm{m}-630>\mathrm{AW} / \mathrm{m}-700>\mathrm{AW} / \mathrm{m}-750$. The $\mathrm{AW} / \mathrm{m}-630$ sample retained more chemisorbed ammonia as the catalyst was heated to $400{ }^{\circ} \mathrm{C}$ than the other catalysts did. In other words, AW/m-630 has more strong Brönsted acid sites than AW/m-700 and than AW/m-750. Also the strength of the Brönsted acid sites in AW/m-750 is the weakest. Among the three catalysts, the Brönsted acid strength in $\mathrm{AW} / \mathrm{m}-700$ is intermediate.

Previously, we have employed the XPS of the N 1s peak of adsorbed pyridine to investigate the types and strengths of acid sites displayed by sulfated zirconia catalysts by resolving the spectra position and intensity [9]. We found the $\mathrm{N} 1$ s peaks were rather broad and we de-convoluted the peaks into a distribution of three different acidic sites of a range of acid strength [9]. In our case here, the fraction of strong Brönsted acid sites in the total Brönsted acidity (or overall acidity) is the highest in AW/ $\mathrm{m}-630$ but moderate in $\mathrm{AW} / \mathrm{m}-700$ (figure not shown), which is in agreement with the DRIFT results. Relatively, the fraction of Lewis acid is increased as the temperature of calcination is increased.

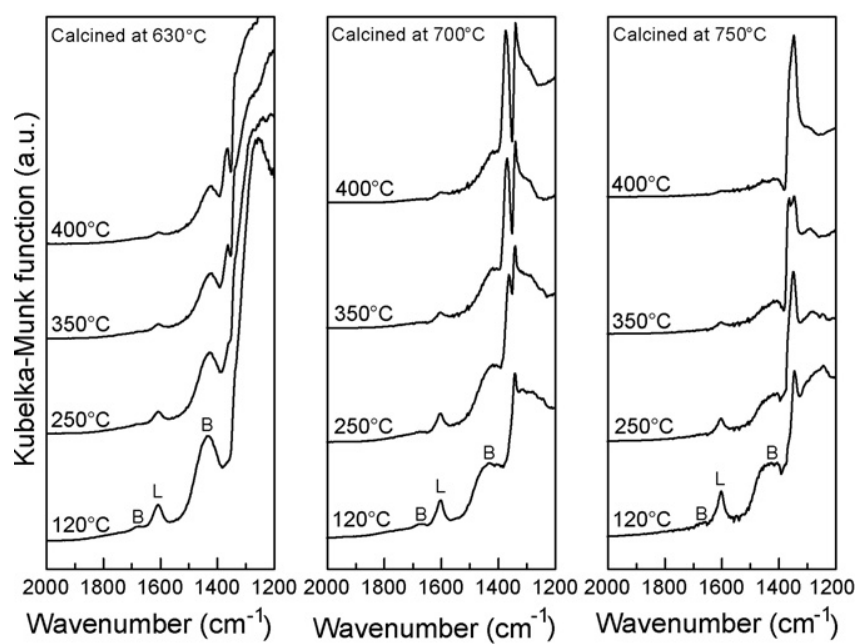

Fig. 4. DRIFT spectra for the desorption of chemisorbed ammonia on AW/m630, AW/m-700, and AW/m-750. These spectra were normalized to the same intensity of the $\mathrm{m}-\mathrm{ZrO}_{2}$ lattice band at about $1342 \mathrm{~cm}^{-1}$.

\subsection{The dispersion of tungstate}

It is known the catalytic activity of tungstated zirconia depends crucially on the degree of dispersion of $\mathrm{WO}_{x}$ on the surface of zirconia [14]. We here employ three techniques to investigate the dispersion of tungstate. UV-vis spectra are sensitive to the dispersion of tungstate. EXAFS analysis can help us to reveal the radial distribution function (RDF) of various scatters around the central X-ray absorbing atom. X-ray photoelectron spectroscopy (XPS) on the other hand can give the relative surface composition of $\mathrm{W}$ versus $\mathrm{Zr}$.

Comparing the dispersion of $\mathrm{WO}_{x}$ species on $\mathrm{d}-\mathrm{ZrO}_{2}$ and $\mathrm{m}$ $\mathrm{ZrO}_{2}$ by XRD and UV-vis techniques, the XRD peaks characteristic of $\mathrm{WO}_{3}$ crystallites $\left(2 \theta=23.3^{\circ}, 23.8^{\circ}\right.$, and $\left.24.5^{\circ}\right)$ were not detected in AW/d-700 and AW/m-700 samples (Fig. 1). In Fig. 5, the UV-vis spectra of three catalysts are compared. The AW/m-630 sample shows a shoulder absorption band near $430 \mathrm{~nm}$, which is due to $\mathrm{WO}_{3}$. As the calcination temperature was increased from $630{ }^{\circ} \mathrm{C}$ to $700{ }^{\circ} \mathrm{C}$, the characteristic absorption edge $(\sim 430 \mathrm{~nm})$ of crystalline $\mathrm{WO}_{3}$ disappeared and we have a fully dispersed $\mathrm{AW} / \mathrm{m}-700$ catalyst.

Fig. 6 compares the Fourier-transformed W- $\mathrm{L}_{\mathrm{III}}$-edge EXAFS spectra of AW/d-700, AW/m-700, and AW/m-630 catalysts. The data were recorded ex situ at room temperature after a $\mathrm{H}_{2}$ pretreatment at $300{ }^{\circ} \mathrm{C}$. These $\mathrm{RDFs}$ are not corrected for phase shifts. The assignment of peaks was made according to the published work of Wong et al. on zirconia-supported tungsten oxide system [6]. The peaks between $R=0.80$ and $R=1.99 \AA$ in the RDF plots are due to $\mathrm{W}-\mathrm{O}$ bond distances. The distribution of $\mathrm{W}-\mathrm{O}$ distance is rather broad, indicating a much disordered $\mathrm{WO}_{x}$ octahedral polytungstate structure on zirconia. One notes that the $\mathrm{W}-\mathrm{O}$ bond distance of $\mathrm{AW} / \mathrm{m}-700$ and $\mathrm{AW} / \mathrm{m}-630(1.24 \AA)$ is significantly shorter than that of AW/d-700 (1.35 $\AA$ ), indicating that the terminal $\mathrm{H}$ atom bound to the $\mathrm{W}-\mathrm{O}$ may be eliminated more easily in the mesoporous system than that in the dense phase system. In addition, we can

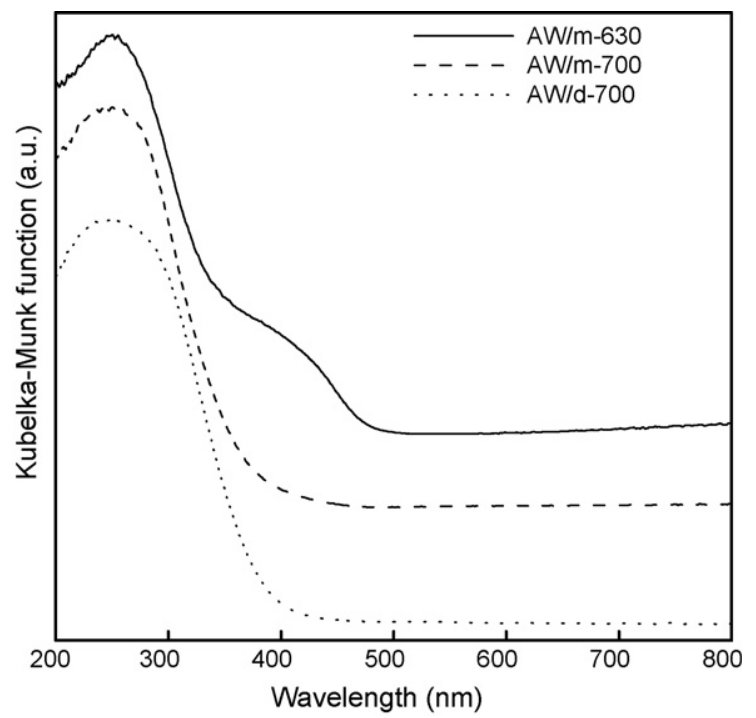

Fig. 5. UV-vis absorption spectra of AW/d-700, AW/m-630, and AW/m-700 catalysts. 


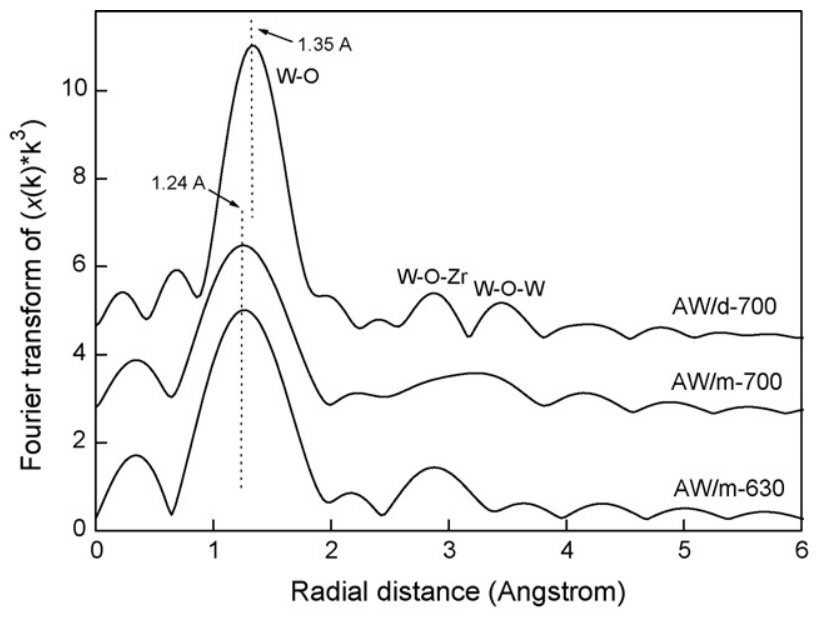

Fig. 6. W-L $\mathrm{L}_{\mathrm{III}}$-edge EXAFS radial distribution functions of AW/d-700, AW/m700 , and AW/m-630 catalysts.

see that the W-O-W peak at $3.46 \AA$ in $\mathrm{AW} / \mathrm{d}-700$ is similar to that of bulk $\mathrm{WO}_{3}[10]$. However, $\mathrm{W}-\mathrm{O}-\mathrm{W}$ and $\mathrm{W}-\mathrm{O}-\mathrm{Zr}$ peaks in the RDF spectra of AW/m-700 collapse into a broad peak, indicating highly dispersed disordered tungstate clusters on the surface of zirconia. We propose that this is because the mesoporous zirconia itself can provide more continuous surface area for $\mathrm{WO}_{x}$ species to disperse better. From Fig. 6, AW/m-630 seems to disperse less well than the AW/m-700 catalyst.

The XPS spectra of $\mathrm{W} 4 \mathrm{f}$ and $\mathrm{Zr} 4 \mathrm{p}$ (left) and $\mathrm{Zr} 3 \mathrm{~d}$ (right) of AW/d-700 and AW/m-700 are shown in Fig. 7. For the W $4 \mathrm{f}$ energy region in the range of $32.3-39.5 \mathrm{eV}$, the complex features were deconvoluted into two doublets corresponding to $\mathrm{W}^{5+}$ and $\mathrm{W}^{6+}$. The characteristics first peaks of $\mathrm{W}^{5+}$ and $\mathrm{W}^{6+}$ are at $34.7 \mathrm{eV}$ and $35.6 \mathrm{eV}$, respectively. The ratios of the two species were found to be $\mathrm{W}^{5+} / \mathrm{W}^{6+}=0.64$ for $\mathrm{AW} / \mathrm{d}-700$ and 0.77 for $\mathrm{AW} / \mathrm{m}-700$. The surface $\mathrm{W} / \mathrm{Zr}$ ratios of samples can be determined from the ratio of the integrated area of W 4f XPS peaks to the integrated area of $\mathrm{Zr} 3 \mathrm{~d}$ XPS peaks with
Table 2

W 4f XPS fitting results

\begin{tabular}{lllll}
\hline Sample & BE $(e V)$ & Assignment & W $(\%)$ & W/Zr \\
\hline AW/d-700 & 35.6 & $\mathrm{~W}^{6+}$ & 61 & 0.155 \\
& 34.7 & $\mathrm{~W}^{5+}$ & 39 & \\
AW/m-700 & 35.7 & $\mathrm{~W}^{6+}$ & 56 & 0.088 \\
& 34.9 & $\mathrm{~W}^{5+}$ & 44 & \\
\hline
\end{tabular}

consideration of the atomic sensitivity factors of $\mathrm{W}$ and $\mathrm{Zr}$. The fitting results of the XPS are compiled in Table 2.

The surface $\mathrm{W} / \mathrm{Zr}$ ratio is a good measure of the degree of dispersion of $\mathrm{W}$ on the surface. One could have the same loading of $\mathrm{W}$ per unit area while giving different surface $\mathrm{W} / \mathrm{Zr}$ ratios because of different degrees of aggregation of $\mathrm{WO}_{x}$. Multilayer structures for $\mathrm{WO}_{x}$ would give a higher value of $\mathrm{W} /$ $\mathrm{Zr}$ compared to monolayer ones. In our catalyst, surface ratios are determined to be $\mathrm{W} / \mathrm{Zr}=0.155$ for $\mathrm{AW} / \mathrm{d}-700$ and 0.088 for $\mathrm{AW} / \mathrm{m}-700$. The results show that the dispersion of $\mathrm{WO}_{x}$ on the surface of zirconia is better on mesoporous zirconia than on the dense phase zirconia.

The relative richness of $\mathrm{W}(\mathrm{V})$ can also be checked by the W$\mathrm{L}_{\mathrm{III}}$-edge XANES spectra of the catalysts. Fig. 8 shows the W$\mathrm{L}_{\mathrm{III}}$-near edge white line of the three samples. The mesoporous catalysts $\mathrm{AW} / \mathrm{m}-630$ and $\mathrm{AW} / \mathrm{m}-700$ possess a peak that is shifted by $1.8 \mathrm{eV}$ to lower photon energy. This indicates a lower valence of $\mathrm{W}$ for the mesoporous sample, in agreement with the conclusion reached by XPS analysis.

\subsection{Catalytic properties of $\mathrm{AW} / \mathrm{m}-\mathrm{ZrO}_{2}$ catalysts}

As $\mathrm{AW} / \mathrm{m}-\mathrm{ZrO}_{2}$ has more acid sites and stronger acid strength than $\mathrm{AW} / \mathrm{d}-\mathrm{ZrO}_{2}$, it is interesting to look at its performance in catalytic reactions. We choose a well-studied reaction system, the $n$-butane isomerization reaction, which can be catalyzed by highly dispersed $\mathrm{WO}_{x}$ species on the zirconia surface.

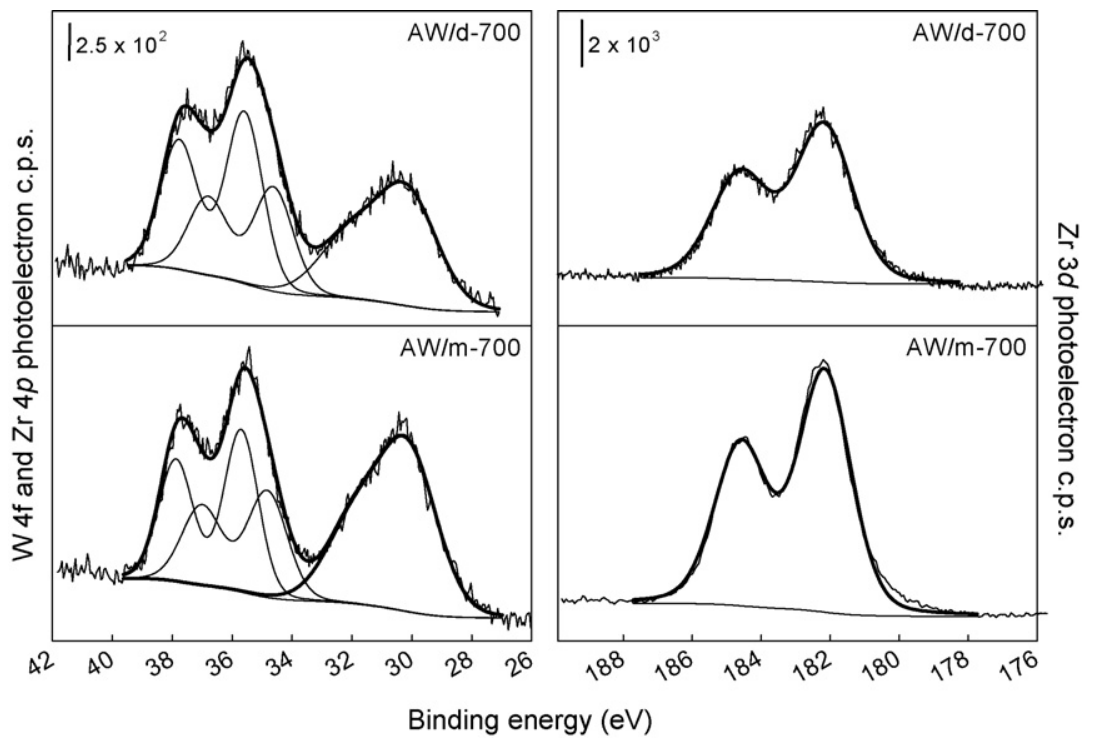

Fig. 7. W 4f and Zr 4p XPS spectra (left) and Zr 3d XPS spectra (right) of AW/d-700 and AW/m-700. (Samples were treated with $\mathrm{H}_{2}$ at $300{ }^{\circ} \mathrm{C}$ for $1 \mathrm{~h}$.) 


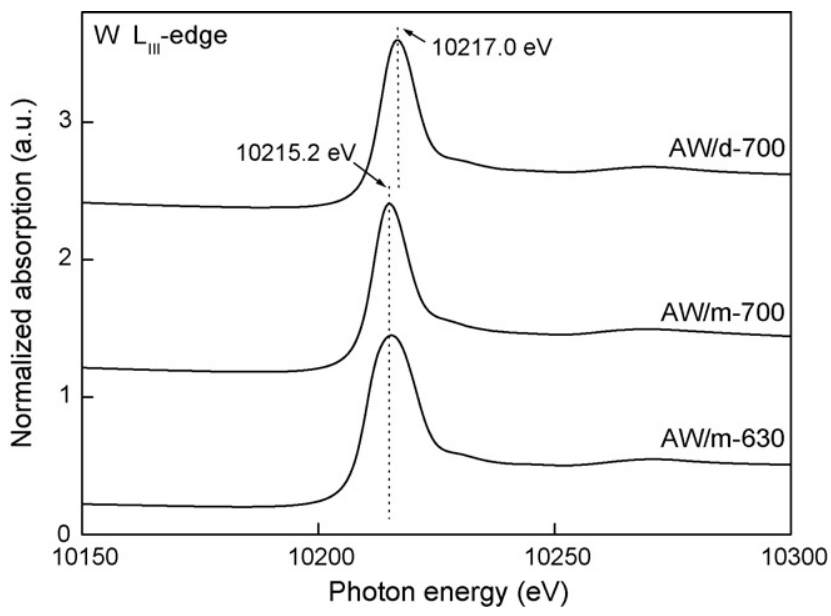

Fig. 8. W-L $\mathrm{III}$-edge XANES spectra of AW/d-700, AW/m-700, and AW/m-630 catalysts.

Fig. 9 compares the catalytic activities of some selected W/ $\mathrm{m}-\mathrm{ZrO}_{2}$, and $\mathrm{AW} / \mathrm{m}-\mathrm{ZrO}_{2}, \mathrm{AW} / \mathrm{d}-\mathrm{ZrO}_{2}$ catalysts, and that of un-dopped $\mathrm{m}-\mathrm{ZrO}_{2}$ support in $n$-butane isomerization reaction at $250{ }^{\circ} \mathrm{C}$. Especially, we studied the effect of calcination temperature. Indeed, one can see that $\mathrm{AW} / \mathrm{m}-\mathrm{ZrO}_{2}$ catalyst has much higher activity than the dense phase $\mathrm{AW} / \mathrm{d}-\mathrm{ZrO}_{2}$ catalyst due to the enhanced acid sites and acid strength. If we compare the initial activities, we do see a higher activity for the catalyst calcined at lower temperature. This is in agreement with the higher amount of observed Brönsted acid sites for the AW/m630 sample. After $1 \mathrm{~h}$ or so, however, the catalytic activity of AW/m-630 drops rapidly due to coking. Then the steady state activity of AW/m-700 becomes higher than that of AW/m-630 and its activity profile is also more stable. For catalyst calcined at $750{ }^{\circ} \mathrm{C}$, the steady state activity is even lower. It seems the framework structure of $\mathrm{m}-\mathrm{ZrO}_{2}$ starts to collapse in the catalyst AW/m-750 as shown by the decrease in both its surface area and pore volume, whereas the tetragonal phase of zirconia is not yet well-developed in AW/m-630. Therefore, $700{ }^{\circ} \mathrm{C}$ seems to be the optimal calcination temperature for this system and the high

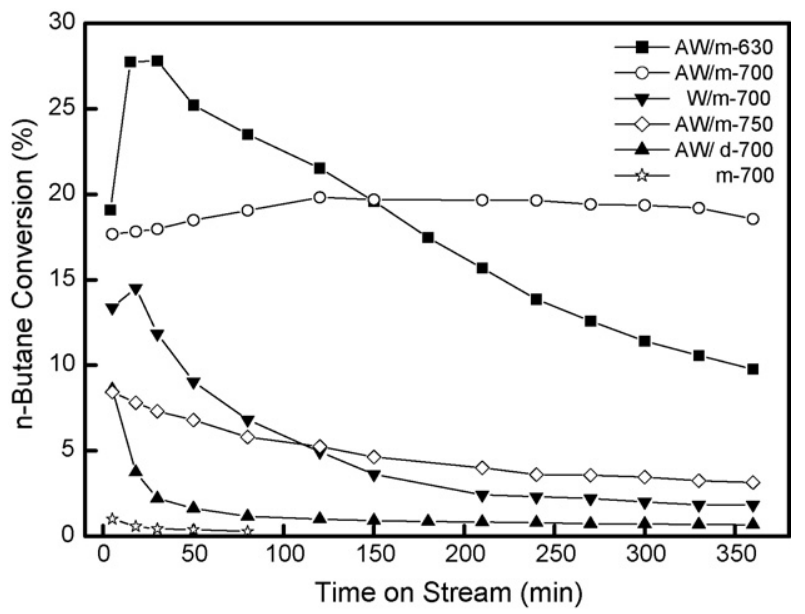

Fig. 9. Catalytic profiles of W/m- $\mathrm{ZrO}_{2}, \mathrm{AW} / \mathrm{m}-\mathrm{ZrO} 2, \mathrm{AW} / \mathrm{d}-\mathrm{ZrO}_{2}$, and $\mathrm{m}-\mathrm{ZrO}_{2}$ catalysts in $n$-butane isomerization reaction at $250{ }^{\circ} \mathrm{C}$. porosity and moderate acidity made $\mathrm{AW} / \mathrm{m}-700$ an active and stable catalyst. For the purpose of background check, we also measure the activity for the starting materials $\mathrm{m}-\mathrm{ZrO}_{2}$, i.e. the mesoporous zirconia without any loadings of $\mathrm{Al}$ or W. As expected, it exhibits a very low activity as shown in Fig. 9.

\section{Discussion}

Our catalyst AW/m-700 performed exceptionally well at a low temperature of $250{ }^{\circ} \mathrm{C}$ compared to other tungstated zirconia-based catalyst reported so far which generally required a reaction temperature higher than $300{ }^{\circ} \mathrm{C}[6,7,10,15]$.

The promotion of catalytic activity by $\mathrm{Al}$ may be through two different effects: (a) the formation of more strong acid sites [6], (b) the increased redox activity of $\mathrm{W}$ where butane molecules are activated by dehydrogenation on well-dispersed polyoxotungstate via a redox process [16]. Both processes may be important for the catalytic isomerization of alkanes.

Recent investigations indicate that both of the above effects are controlled by $\mathrm{WO}_{x}$ surface density (at. $\mathrm{W} \mathrm{nm}{ }^{-2}$ ) $[14,17,18]$. The nearly monolayer regime (corresponding to our sample) is characterized by distorted $\mathrm{WO}_{x}$ species that are well dispersed on the $\mathrm{ZrO}_{2}$ surface [19]. In order to achieve a better dispersion of $\mathrm{WO}_{x}$ on the surface, we need a zirconia support with high surface area, porosity, and thermal stability. These requirements are all met by mesoporous zirconia, $\mathrm{m}-\mathrm{ZrO}_{2}$. The variations of activity for $\mathrm{AW} / \mathrm{m}-\mathrm{ZrO}_{2}$ catalysts calcined at different temperatures may be correlated to the surface density values of tungstate, as shown in Table 1. The optimum $\mathrm{W}$ surface density for catalysis, at $3.1 \mathrm{~W} \mathrm{~nm}^{-2}$, is a little below the monolayer density.

We note that in our samples a higher temperature of calcination leads to pore expansion and lower surface area. Comparing AW/m-630, AW/m-700, and AW/m-750 in Table 1, one would expect lower dispersion of the $\mathrm{WO}_{x}$ species on zirconia at higher temperature of calcinations, which in turn would lead to lower acidity and redox capability. However, catalytic activities cannot simply be explained by the surface area effect alone, since $\mathrm{d}-\mathrm{ZrO}_{2}$ and $\mathrm{m}-\mathrm{ZrO}_{2}$ possess about the same surface area. We have to consider the dispersion effect on the distribution of acidity and correlate with the catalytic performance of $\mathrm{AW} / \mathrm{m}-\mathrm{ZrO}_{2}$ catalysts. In addition to surface density, one is thus also concerned with the degree of dispersion. The more extensive the $\mathrm{W} / \mathrm{Zr}$ contact is, the more active the catalyst will be. In other words, the bulk $\mathrm{WO}_{3}$ phase is inactive. In this paper, we measure the degree dispersion by surface W/Zr ratio determined by XPS (Fig. 7). Previously, Di Gregorio and Keller [19], using the same XPS technique, have shown a non-linear increase of $\mathrm{W} / \mathrm{Zr}$ with respect to $\mathrm{W} \%$ loading. Near monolayer the ratio $\mathrm{W} / \mathrm{Zr}$ is about 0.08 and it increases with $\mathrm{W}$ loading up to about 0.25 in their tungstated zirconia catalyst. In our catalysts, it is interesting to compare the two samples of AWZ/d-700 and AWZ/m-700. They have the same surface area, but the mesoporous zirconia sample AWZ/m-700 has much better dispersion (lower $\mathrm{W} / \mathrm{Zr}$ value). This correlates well with the higher amount of surface acidity detected in $\mathrm{AZW} / \mathrm{m}-\mathrm{ZrO}_{2}$. This may partially explain 
why we observe a better catalytic activity in AWZ/d-700. It seems the continuous channel wall of mesoporous zirconia with surfactant in it provides one a better surface to disperse uniformly the polytungstate species. UV-vis, EXAFS and XPS studies all indicate higher degrees of dispersion of the tungstate on the mesoporous zirconia surfaces.

The degrees of dispersion of tungstates affect both the redox and acidic properties of the WZ catalyst [18-20]. For characterizing the redox tendency of AWZ, we measured the relative ratio of the two species $\mathrm{W}^{5+} / \mathrm{W}^{6+}$. Our investigation by XPS technique found that the addition of $\mathrm{Al}$ did help the dispersion of tungstates on zirconia and did lead to the more active $\mathrm{W}^{5+}$ species [10]. Since the Al-loading in mesoporous supported $\mathrm{AW} / \mathrm{m}-\mathrm{ZrO}_{2}$ is higher than that in dense phase supported catalyst $\mathrm{AW} / \mathrm{d}-\mathrm{ZrO}_{2}$, the pentavalent $\mathrm{W}^{5+}$ species is higher in the mesoporous catalyst $\mathrm{AW} / \mathrm{m}-\mathrm{ZrO}_{2}$. Recently, Kuba et al. have associated the initiation of $\mathrm{C}-\mathrm{H}$ bond breaking and dehydrogenation with the reducibility of surface $\mathrm{W}$ species [21]. The butane molecules are activated by dehydrogenation on well-dispersed polyoxotungstate via a redox process. Then the resulting alkenes are protonated on the acidic sites. Since we found the $\mathrm{W}^{5+} / \mathrm{W}^{6+}$ ratio to be higher for the mesoporous sample, the improved redox pair of $\mathrm{W}^{5+} / \mathrm{W}^{6+}$ in promoted mesoporous WZ is accompanied by the easier activation of alkanes.

We would like to put emphasis on the much lower calcination temperature of $700{ }^{\circ} \mathrm{C}$ of our catalyst, which leads to the presence of more Brönsted acid sites while calcination at higher temperature would convert some Brönsted acid to Lewis acid. In the reported works on tungstated zirconia catalysts, the calcination temperature was always higher than $800{ }^{\circ} \mathrm{C}$ [7,14,21-25], which would lead to less surface Brönsted sites while giving too many Lewis acid sites. It seems that the relative concentration of Brönsted acid sites in the catalyst should be moderate for a good performing catalyst, as in the case of AW/m-700. Too many strong Brönsted acid sites would lead to coking and thus rapid decay of the catalytic activity. Although a high relative concentration of strong Brönsted acid sites in AW/m-630 can protonate butene rapidly (high initial activity), they are also more susceptible to coke formation (thus a fast decay rate). Indeed, the amount of coke in the spent catalyst of AW/m-630 (0.38 wt.\%) is higher than in AW/m-700 (not detected). On the other hand, too low a concentration of the Brönsted acid sites is also not effective for the reaction. It seems the effective acidic sites result from polytungstate species. Highly dispersed monomeric species do not seem to be effective in the acidic catalysis [14]. In fact, recently Lebarbier et al. [26] have shown that the surface density of $\mathrm{W}$ on $\mathrm{WZ}$ needs to be above a certain threshold to be effective in acid catalysis. The activity thresholds are 1.3 at. $\mathrm{W} \mathrm{nm}^{-2}$ for propanol dehydration and 2.3 at. $\mathrm{W} \mathrm{nm}^{-2}$ for hexane isomerization [26]. The surface $\mathrm{W}$ densities of our catalysts are above 2.1 at. $\mathrm{W} \mathrm{nm}{ }^{-2}$.

Also, we would like to emphasize that the hydrogen adsorbed on the surface of tungstated zirconia would also contribute to acidity. It is known that the Brönsted acid sites form on $\mathrm{WO}_{x}$ domains due to the delocalized electrons from $\mathrm{H}$ atoms. In fact, $\mathrm{Pt}$ promoted tungstated zirconia under hydrogen is much more active for catalysis than without hydrogen [27]. Barton et al. [18] suggested catalysts with crystal $\mathrm{WO}_{3}$ presented on the surface of $\mathrm{ZrO}_{2}$ are less active because crystal $\mathrm{WO}_{3}$ decreases the ability of accepting electrons from $\mathrm{H}$ atoms to form the Brönsted acids and some $\mathrm{H}$ atoms are accommodated inside the crystal $\mathrm{WO}_{3}$ where they are inaccessible to reactant molecules. The highly dispersed $\mathrm{WO}_{x}$ species can form Brönsted acid sites more easily under hydrogen environment.

In summary, the extensive continuous surface of $\mathrm{m}-\mathrm{ZrO}_{2}$ seems to favor better dispersion and better reducibility of the surface tungstate species. Alumina also helps in the dispersion. This good dispersion of $\mathrm{W}$ leads to more and stronger acid sites. The reducibility of $\mathrm{W}$ helps in two ways in catalysis: it favors electron transfer-induced $\mathrm{C}-\mathrm{H}$ bond activation and thus the initiation of the reaction chain; then the hydrogen would decompose on the surface to generate the proton species, which also increases acidity. However, further researches into the details of catalytic sites in tungstated zirconia solid acid would certainly be welcome.

\section{Conclusion}

In this research, we successfully synthesized $\mathrm{AW} / \mathrm{m}-\mathrm{ZrO}_{2}$ catalyst with mesoporous structure. In comparison to $\mathrm{AW} / \mathrm{d}$ $\mathrm{ZrO}_{2}$, synthesized without template, $\mathrm{AW} / \mathrm{m}-\mathrm{ZrO}_{2}$ has a higher activity for $n$-butane isomerization at a lower calcination temperature of $700{ }^{\circ} \mathrm{C}$ and at a lower reaction temperature of $250{ }^{\circ} \mathrm{C}$. The increased activity, which reaches nearly $30 \%$ of that for alumina-promoted sulfated zirconia (AS/m-630), is dependent on the promotion of $\mathrm{Al}$ and the mesostructure $\mathrm{ZrO}_{2}$. As a result, we obtained a well-dispersed tungstate on zirconia while the mesostructure $\mathrm{ZrO}_{2}$ favors the formation of stronger acid sites and enhanced the total acid sites.

A notable characteristic of $\mathrm{AW} / \mathrm{m}-\mathrm{ZrO}_{2}$ catalysts is that they are composed of mixed oxides without noble metal, which would make it more tolerant to sulfur contents in the feed gas. More importantly, tungstated zirconia catalyst is much more stable than the sulfated zirconia catalyst which would lose sulfur during long-term reactions. The high activity and stability of this catalyst at low temperature make it a new kind of halogen-free solid acid catalyst that is friendly to the environment.

\section{Acknowledgments}

This work was supported by a grant from the National Science Council of Taiwan through Academy Excellent program (NSC-94-2752-M-002-004-PAE). C.-L. Chen is thankful for the financial support from the National Science Foundation of China (Project 20476047).

\section{References}

[1] M. Hino, K. Arata, J. Chem. Soc., Chem. Commun. (1988) 1259.

[2] J.C. Yori, C.L. Pieck, J.M. Parera, Appl. Catal. A 181 (1999) 5.

[3] M. Scheithauer, T.K. Cheung, R.E. Jentoft, R.K. Grasselli, B.C. Gates, H. Knözinger, J. Catal. 180 (1998) 1. 
[4] S.R. Vaudagna, S.A. Canavese, R.A. Comelli, N.S. Fígoli, Appl. Catal. A 168 (1998) 93.

[5] U. Ciesla, M. Fröba, G. Stucky, F. Schüth, Chem. Mater. 11 (1999) 227.

[6] S.T. Wong, T. Li, S. Cheng, J.F. Lee, C.Y. Mou, J. Catal. 215 (2003) 45.

[7] X.R. Chen, C.L. Chen, N.P. Xu, C.Y. Mou, Catal. Today 93-95 (2004) 129.

[8] X.R. Chen, C.L. Chen, N.P. Xu, S. Han, C.Y. Mou, Catal. Lett. 85 (2003) 177.

[9] J.H. Wang, C.Y. Mou, Appl. Catal. A 286 (2005) 128.

[10] X.R. Chen, Y.Q. Du, C.L. Chen, N.P. Xu, C.Y. Mou, Catal. Lett. 111 (2006) 187.

[11] D.G. Barton, S.L. Soled, G.D. Meitzner, G.A. Fuentes, E. Iglesia, J. Catal. 181 (1999) 57.

[12] F.C. Jentoft, A. Hahn, J. Kröhnert, G. Lorenz, R.E. Jentoft, T. Ressler, U. Wild, R. Schlögl, C. Häßner, K. Köhler, J. Catal. 224 (2004) 124.

[13] S.T. Wong, T. Li, S. Cheng, J.F. Lee, C.Y. Mou, Appl. Catal. A 296 (2005) 90.

[14] C.D. Baertsche, S.L. Soled, E. Iglesia, J. Phys. Chem. B 105 (2001) 1320.

[15] X.R. Chen, C.L. Chen, N.P. Xu, C.Y. Mou, Chin. J. Catal. 24 (2003) 924.

[16] S. Kuba, M. Che, R.K. Grasselli, H. Knözinger, J. Phys. Chem. B 107 (2003) 3459.
[17] T.M. Vu, J. Van Gestel, J.P. Gilson, C. Collet, J.P. Dath, J.C. Duchet, J. Catal. 231 (2005) 453.

[18] D.G. Barton, M. Shtein, R.D. Wilson, S.L. Soled, E. Iglesia, J. Phys. Chem. B 103 (1999) 630.

[19] F. Di Gregorio, V. Keller, J. Catal. 225 (2004) 45.

[20] M.A. Cortes-Jacome, J.A. Toledo, C. Angeles-Chavez, M. Aguilar, J.A. Wang, J. Phys. Chem. B 109 (2005) 22730.

[21] S. Kuba, P.C. Heydorn, R.K. Grasselli, B.C. Gates, M. Che, H. Knözinger, Phys. Chem. Chem. Phys. 3 (2001) 146.

[22] G. Larsen, L.M. Petkovic, Appl. Catal. A 148 (1996) 155.

[23] J.G. Santiesteban, J.C. Vatuli, S. Han, R.D. Bastian, C.D. Chang, J. Catal. 168 (1997) 431.

[24] A. Barrera, J.A. Montoya, M. Viniegra, J. Navarrete, G. Espinosa, A. Vargas, P. del Angel, G. Perez, Appl. Catal. A 290 (2005) 97.

[25] R.A. Boyse, E.I. Ko, J. Catal. 171 (1997) 191.

[26] V. Lebarbier, G. Clet, M. Houalla, J. Phys. Chem. B 110 (2006) 13905.

[27] T. Li, S.T. Wong, M.C. Chao, H.P. Lin, C.Y. Mou, S.F. Cheng, Appl. Catal. A 261 (2004) 21. 